\title{
Ginsenoside-Rg5 induces apoptosis and DNA damage in human cervical cancer cells
}

\author{
LI-DAN LIANG, TAO HE, TING-WEI DU, YONG-GANG FAN, DIAN-SEN CHEN and YAN WANG
}

\begin{abstract}
Department of Obstetrics and Gynecology, The First Affiliated Hospital of Henan University of Science and Technology, Luoyang, Henan 471003, P.R. China
\end{abstract}

Received December 9, 2013; Accepted September 18, 2014

DOI: $10.3892 / \mathrm{mmr} .2014 .2821$

\begin{abstract}
Panax ginseng is traditionally used as a remedy for cancer, inflammation, stress and aging, and ginsenoside- $\operatorname{Rg} 5$ is a major bioactive constituent of steamed ginseng. The present study aimed to evaluate whether ginsenoside- $\operatorname{Rg} 5$ had any marked cytotoxic, apoptotic or DNA-damaging effects in human cervical cancer cells. Five human cervical cancer cell lines (HeLa, MS751, C33A, Me180 and HT-3) were used to investigate the cytotoxicity of ginsenoside- $\operatorname{Rg} 5$ using a 3-(4,5-dimethylthiazol-2-yl)-2,5-diphenyltetrazolium bromide assay. Additionally, the effects of ginsenoside- $\operatorname{Rg} 5$ on the apoptosis of HeLa and MS751 cells were detected using DNA ladder assays and flow cytometry. DNA damage was assessed in the HeLa and MS751 cells using alkaline comet assays and by detection of $\gamma \mathrm{H} 2 \mathrm{AX}$ focus formation. The HeLa and MS751 cells were significantly more sensitive to ginsenoside- $\operatorname{Rg} 5$ treatment compared with the C-33A, HT-3 and Me180 cells. As expected, ginsenoside- $\operatorname{Rg} 5$ induced significant concentration- and time-dependent increases in apoptosis. In addition, ginsenoside- $\operatorname{Rg} 5$ induced significant concentration-dependent increases in the level of DNA damage compared with the negative control. Consistent with the comet assay data, the percentage of $\gamma \mathrm{H} 2 \mathrm{AX}$-positive HeLa and MS751 cells also revealed that ginsenoside-Rg5 caused DNA double-strands to break in a concentration-dependent manner. In conclusion, ginsenoside- $\operatorname{Rg} 5$ had marked genotoxic effects in the $\mathrm{HeLa}$ and MS751 cells and, thus, demonstrates potential as a genotoxic or cytotoxic drug for the treatment of cervical cancer.
\end{abstract}

Correspondence to: Professor Tao He, Department of Obstetrics and Gynecology, The First Affiliated Hospital of Henan University of Science and Technology, 24 Jinghua Road, Luoyang Henan 471003, P.R. China

E-mail: tougao0101@163.com

Key words: cervical cancer, ginsenoside-Rg5, DNA damage, apoptosis

\section{Introduction}

Cervical cancer, which develops in the tissues on the surface of the cervix, is one of the most common types of cancer affecting females worldwide, with $>510,000$ new cases and 288,000 mortalities per year (1). The main risk factor for developing cervical cancer is contraction of human papillomavirus (HPV), which is the cause of almost all cases of cervical cancer (2). The introduction of HPV vaccines has afforded major advances in the prevention and management of cervical cancer; however, current vaccines can prevent only $\sim 70 \%$ of cases (1). HPV infections are often asymptomatic and transient, but can promote in situ cervical pre-cancer, although the majority of cases spontaneously regress, indicating that HPV alone is not sufficient to cause cervical cancer. In addition, females in the early stages of cervical cancer may not exhibit any symptoms (2). Regular Pap tests are now more common, making cervical cancer more detectable (3), and the early detection of cervical cancer tends to lead to more favorable treatment outcomes compared with the detection of more advanced stages (4).

There are several treatment options for cervical cancer, including radiation and chemotherapy, which can be used in conjunction with various herbal remedies $(5,6)$. While controversial in the medical field, herbal treatments can produce positive results when used alongside more standard therapies (7). Furthermore, traditional Chinese medicine (TCM) combined with a healthy lifestyle can often lead to the complete resolution of mild and moderate diseases (8). Several doctors have used the TCM ginseng ginsenoside- $\mathrm{Rh} 2$ in an attempt to further improve immune system function, inhibit cancer cell proliferation and induce the transformation of normal cells in patients with cervical cancer. Additionally, when used at a dose of $60 \mathrm{~g} / \mathrm{kg}$, sophora root has a significant effect on the development and progression of cervical cancer in mice (http://www.acupuncture.com/herbs/cancerherbc.htm. Accessed March 4, 2013).

TCM is a holistic medicinal system, which includes the use of herbal medicines, acupuncture and moxibustion, tuina, dietary therapy and qigong. TCM has specific methods for diagnosis and treatment, primarily associated with differentiation of the syndrome and the prescription of herbal formulas (9). A systematic review of case reports reveals that there is an abundance of support for the use of TCMs as therapy for a 
variety of types of cancer, suggesting the potential benefits of these therapies (10).

The use of ginseng as a TCM is common in the treatment of diabetes, cancer, stress and allergies in several Asian countries (11). In particular, heat-processed ginseng, which has been used for the treatment of cancer, inflammation and aging, contains ginsenoside-Rg5 (Fig. 1) as a main constituent (12-14); ginsenoside- $\operatorname{Rg} 5$ belongs to the family of protopanaxadiol ginsenosides $(12,13)$ and has been demonstrated to exhibit marked anticancer activity $(15,16)$, antidermatitic activity (17), anti-inflammatory effects in mouse lungs (18), neuroprotective effects (19) and microglial activation (20). However, the effects of ginsenoside- $\operatorname{Rg} 5$ on cervical cancer remain to be elucidated. During screening for the identification of TCMs that inhibit the progression of cervical cancer, heat-processed ginseng and its main constituent ginsenoside- $\operatorname{Rg} 5$ potently induced apoptosis and DNA damage in human cervical cancer cells in vitro. Therefore the present study investigated the applicability of ginsenoside-Rg5 as a potential cytotoxic or genotoxic drug for the treatment of cervical cancer.

\section{Materials and methods}

Cell lines. The human cervical cancer cell lines, C-33A (cat. no. HTB-31), HT-3 (cat. no. HTB-32), Me180 (cat. no. HTB-33) and MS751 (cat.no. HTB-34), were obtained from American Type Culture Collection (Manassas, VA, USA). HeLa cells, derived from human cervical carcinoma, were purchased from the Cell Bank of the Type Culture Collection of the Chinese Academy of Sciences (Shanghai, China). The HeLa cells were cultured in Dulbecco's modified Eagle's medium (DMEM) supplemented with $10 \%$ fetal bovine serum (FBS) and 1\% streptomycin and penicillin, followed by incubation at $37^{\circ} \mathrm{C}$ in a $5 \% \mathrm{CO}_{2}$ incubator. The $\mathrm{C} 33 \mathrm{~A}$ cells were cultured in DMEM containing l-glutamine, $10 \%$ FBS, $1 \%$ non-essential amino acids and $1 \%$ sodium pyruvate. The HT-3 and Me180 cells were cultured in McCoy's medium (Sigma-Aldrich, St. Louis, MO, USA) with l-glutamine and 10\% FBS. The MS751 cells were cultured in Eagle's minimum essential medium (Sigma-Aldrich) with l-glutamine, $10 \%$ FBS, $1 \%$ non-essential amino acids and $1 \%$ sodium pyruvate.

Chemicals and reagents. Ginsenoside-Rg5 (purity>95\%) was provided by Dr WM Zhao at the Shanghai Institute of Materia Medica of the Chinese Academy of Sciences (Shanghai, China). Dimethylsulfoxide, Trypan blue, low melting agarose, 4',6-diamidino-2-phenylindole (DAPI), normal melting agarose, 2-amino-2-(hydroxymethyl)-1,3-propanediol, sodium dodecyl sulfate, ethylenediaminetetraacetic acid, 3-(4,5-dimethylthiazol-2-yl)-2,5-diphenyltetrazolium bromide (MTT), N-methyl-N-nitro-N-nitrosoguanidine (MNNG, inducing DNA damage), Tween 20 and paraformaldehyde were obtained from Sigma-Aldrich. Propidium iodide (PI) (21) and DMEM were obtained from Gibco Life Technologies (Carlsbad, CA, USA). The Apoptosis Detection kit I was obtained from BD Pharmingen San Diego, CA, USA). Triton $\mathrm{X}-100$, ethidium bromide, FBS, xylene cyanol and bromphenol blue were obtained from Shanghai Sangon Biotech Co., Ltd. (Shanghai, China).
Cell viability assessment. The cells were seeded into 96-well plates at a density of $5 \times 10^{4}$ cells per well and left overnight for cell adherence. Cell viability was determined between 12 and $48 \mathrm{~h}$ in the presence or absence of metformin using an MTT assay (22). Plates were read using an Automated Microplate Reader (Multiskan EX; Lab Systems, Helskinki, Finland) at a test wavelength of $570 \mathrm{~nm}$.

DNA extraction and the detection of DNA fragmentation. The HeLa and MS751 cells were treated using ginsenoside-Rg5 at concentrations of $0,2.5$ or $5 \mu \mathrm{M}$ for 12 or $24 \mathrm{~h}$, respectively. Cells treated with $10 \mu \mathrm{M}$ MNNG for $24 \mathrm{~h}$ were used as a positive control (CT). The treated cells were then harvested and washed with phosphate-buffered saline (PBS). DNA was extracted using a Wizard Genomic DNA Purification kit (Promega Corporation, Madison, WI, USA) (23). DNA fragmentation was detected by electrophoresis on a denaturing urea polyacrylamide gel, which was stained using silver nitrate solution (24).

Detection of apoptotic incidence using flow cytometry (25). Cell apoptosis was determined using an Annexin V-fluorescein isothiocyanate (FITC) apoptosis detection kit I (BD Pharmingen). Briefly, the cells were treated with ginsenoside-Rg5 and MNNG at concentrations between 0 and $5 \mu \mathrm{M}$ and at $10 \mu \mathrm{M}$, respectively, for $24 \mathrm{~h}$. The cells were then washed twice with cold PBS and resuspended in $500 \mu \mathrm{l}$ binding buffer at a concentration of $5 \times 10^{5}$ cells $/ \mathrm{ml}$. Subsequently, $5 \mu 1$ annexin V-FITC solution and $5 \mu \mathrm{l}$ PI $(1 \mathrm{mg} / \mathrm{ml})$ were added to the cells at $37^{\circ} \mathrm{C}$ for $30 \mathrm{~min}$. The cells were analyzed using flow cytometry within $1 \mathrm{~h}$. The number of apoptotic cells were counted and represented as a percentage of the total cell count.

Alkaline comet assay. The HeLa and MS751 cells were treated with $0,0.625,1.25,2.5$ or $5 \mu \mathrm{M}$ ginsenoside-Rg5 for $24 \mathrm{~h}$ and were then collected, washed and suspended in PBS (pH 7.4). Subsequently, $30 \mu \mathrm{l}$ cell samples $\left(1 \times 10^{4}\right.$ cells) were suspended in $110 \mu \mathrm{l}$ of $1 \%$ molten low-melting-point agarose at $37^{\circ} \mathrm{C}(26)$. The monosuspension was cast on a microscopic slide that had been covered with a layer of $0.8 \%$ regular-melting-point agarose. Images were captured using an Olympus BX53 fluorescent microscope (Olympus Corporation, Tokyo, Japan) using a filter of 515-560 $\mathrm{nm}$. The extent of DNA migration was determined using an image analysis system (CASPLab; www.casp.of.pl) and the tail length, indicating DNA migration from the nucleus, and tail moment (migrated DNA in the tail multiplied by the tail length) were recorded. All cells treated with MNNG $(10 \mu \mathrm{M})$ were included as positive controls.

$\gamma H 2 A X$ foci staining. The phosphorylation of histone $\mathrm{H} 2 \mathrm{AX}$ as a marker of DNA double-strand breaks (DSBs) was performed, as previously described (24). The HeLa and MS751 cells $\left(5 \times 10^{5}\right)$ were seeded into six-well culture plates and treated with $0,0.625,1.25,2.5$ or $5 \mu \mathrm{M}$ ginsenoside- $\operatorname{Rg} 5$ and $10 \mu \mathrm{M}$ MNNG for $24 \mathrm{~h}$. Following treatment, the cells were fixed in $4 \%$ paraformaldehyde for $15 \mathrm{~min}$, washed with PBS (pH 7.4) and $0.1 \%$ Tween 20 and permeabilized in $1 \%$ Triton-X 100 for 30 min. Following inhibition with fetal bovine serum (Gibco Life Technologies, Carlsbad, CA, USA) 


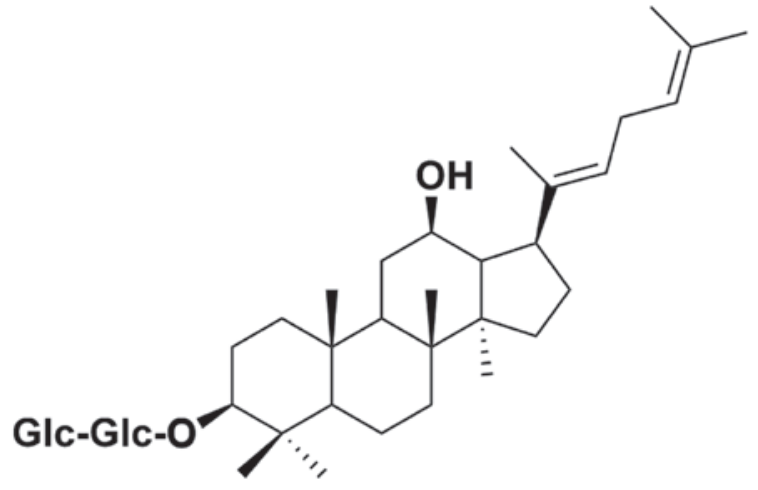

Ginsenoside-Rg5(G-Rg5)

Figure 1. Chemical structure of ginsenoside-Rg5.

for $60 \mathrm{~min}$, the cells were incubated with rabbit monoclonal anti-gH2AX antibodies (1:1,500; Cell Signaling Technology, Inc., Danvers, MA, USA) overnight at $4^{\circ} \mathrm{C}$ and conjugated with Alexa594-conjugated anti-rabbit secondary antibodies (1:360, Cell Signaling Technology, Inc.) for $60 \mathrm{~min}$. For nuclear staining, $1 \mathrm{mg} / \mathrm{ml}$ DAPI was added to the cells and the cells were incubated for $15 \mathrm{~min}$. The cells were then mounted in antifade media and images were captured using an Olympus BX53 fluorescent microscope (Olympus Corporation). The objectives were set at wavelengths of $594 \mathrm{~nm}$ for $\gamma \mathrm{H} 2 \mathrm{AX}$ and $350 \mathrm{~nm}$ for DAPI.

Statistical analysis. All values are expressed as the mean \pm standard error of the mean. The data were analyzed using one-way analysis of variance followed by Student-Newman-Keuls test for multiple comparisons. The Newman-Keuls multiple comparisons test was applied, and $\mathrm{P}<0.05$ and $\mathrm{P}<0.01$ were considered to indicate statistically significant differences.

\section{Results}

Ginsenoside-Rg5 inhibits the growth of cervical cancer cells. To determine whether ginsenoside-Rg5 exerted cytotoxic effects on the cervical cancer cells, the cervical cancer cell lines were exposed to various concentrations of ginsenoside-Rg5 and the cell viability was assessed. Although the sensitivities to the treatment varied depending on the cell line, ginsenoside- $\operatorname{Rg} 5$ treatment at concentrations ranging from 0.625 to $20 \mu \mathrm{M}$ for $48 \mathrm{~h}$ resulted in concentration-dependent cytotoxicity in the cervical cancer cells (Fig. 2A). The half-maximal inhibitory concentration $\left(\mathrm{IC}_{50}\right)$, the concentration at which $50 \%$ of the cells survive, values of the HeLa and MS751 cells were between 2.5 and $10 \mu \mathrm{M}$, while the $\mathrm{IC}_{50}$ values of the $\mathrm{C}-33 \mathrm{~A}$, HT-3 and Me180 cells were all higher than $20 \mu \mathrm{M}$ (Fig. 2A). To further validate the effects of ginsenoside-Rg5, the cells were exposed to $5 \mu \mathrm{M}$ ginsenoside- $\operatorname{Rg} 5$ for 12,24 or $48 \mathrm{~h}$. Ginsenoside- $\operatorname{Rg} 5$ reduced the viability of the cervical cancer cells in a time-dependent manner (Fig. 2B). The HeLa and MS751 cells had a higher sensitivity to the treatment compared with the C-33A, HT-3 and Me180 cells. Thus, these results suggested that ginsenoside- $\operatorname{Rg} 5$ possessed a cytotoxic function in certain cervical cancer cell lines, including HeLa and MS751.
A

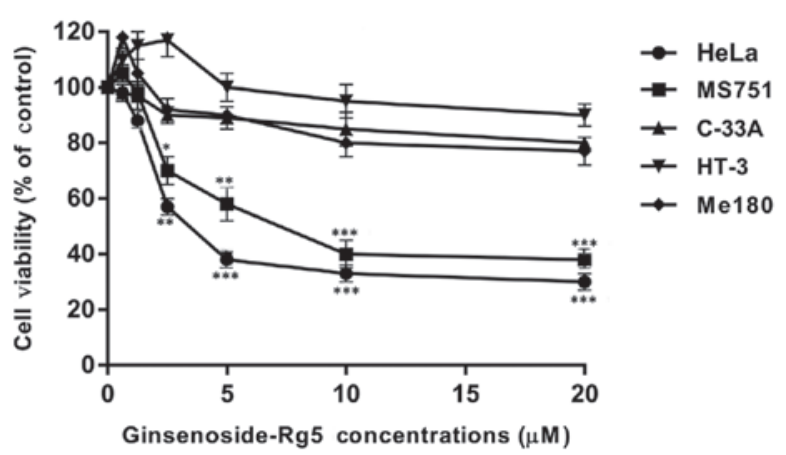

B

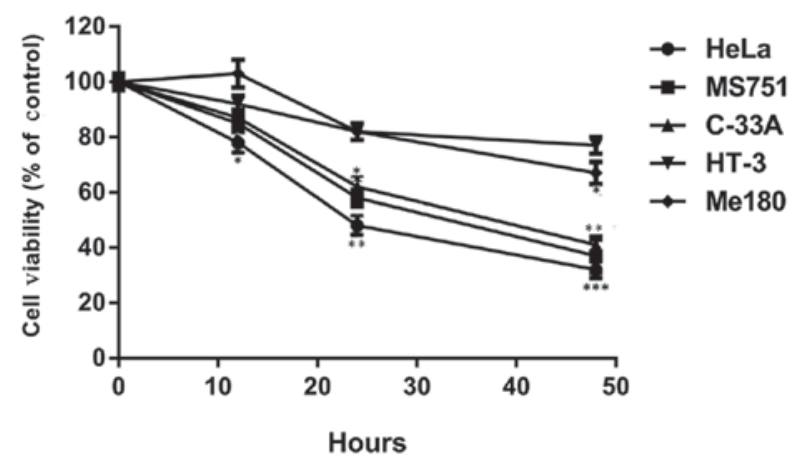

Figure 2. Ginsenoside-Rg5 inhibits the growth of cervical cancer cells. The human cervical cancer cell lines, HeLa, MS751, C33A, Me180 and HT-3, were cultured in medium as described in the Materials and methods. The cells were exposed to (A) $0,0.625,1.25,2.5,5,10$ or $20 \mu \mathrm{M}$ ginsenoside- $\mathrm{Rg} 5$ for $48 \mathrm{~h}$ or (B) $5 \mu \mathrm{M}$ ginsenoside-Rg5 for $0,12,24$, or $48 \mathrm{~h}$. Four hours prior to the final analysis, $100 \mu \mathrm{g} / \mathrm{ml}$ MTT was added to the cell culture medium and the cell viability was determined using an MTT assay. The number of cells in the untreated sample was set as $100 \%$. Data are expressed as the mean \pm standard deviation of three independent experiments. $\mathrm{P}<0.05$, ${ }^{* *} \mathrm{P}<0.01$ and ${ }^{* * *} \mathrm{P}<0.001$, compared with the control. MTT, 3-(4,5-dimethylthiazol-2-yl)-2,5-diphenyltetrazolium bromide.

Ginsenoside-Rg5-induces apoptosis in HeLa and MS751 cells. The HeLa and MS751 cells were significantly more sensitive to ginsenoside-Rg5. Therefore, to determine whether the loss in cell viability induced by ginsenoside- $\operatorname{Rg} 5$ was associated with apoptosis, ginsenoside-Rg5-induced apoptosis was examined in these sensitive cell lines using DNA fragmentation analysis and flow cytometry. As shown in Fig. 3A, ginsenoside- Rg5 induced a ladder-like pattern on the urea polyacrylamide gel electrophoresis (PAGE). The DNA in the untreated cells remained intact. At concentrations of 2.5 and $5 \mu \mathrm{M}$, ginsenoside- $\mathrm{Rg} 5$ led to concentration- and time-dependent increases in DNA fragmentation. In addition, in HeLa and MS751 cells, the fraction of apoptotic cells increased markedly when the cells were treated with 1.25-5 $\mu \mathrm{M}$ ginsenoside-Rg5 (Fig. 3B). Taken together, these results suggested that the anticancer activity of ginsenoside- $\operatorname{Rg} 5$ was mediated, in part, by the induction of apoptosis.

Ginsenoside-Rg5 induces DNA damage in HeLa and MS751 cells. DNA strand breaks were induced by ginsenoside-Rg5, as demonstrated by the comet assays. The alkaline comet assay revealed that DNA fragments migrated to form comet-like images indicative of DNA damage (27). In the control cells, high-density DNA was observed in the comet heads with 
Table I. Parameters of DNA damage from the comet assays of HeLa and MS751 cells exposed to different concentrations of ginsenoside- $\operatorname{Rg} 5$.

Comet assay parameters

Treatment group

\begin{tabular}{lc}
\hline Cell line/compound & Concentration \\
\hline Negative control & $0 \mu \mathrm{M}$ \\
Ginsenoside-Rg5 & $0.625 \mu \mathrm{M}$ \\
& $1.25 \mu \mathrm{M}$ \\
& $2.5 \mu \mathrm{M}$ \\
$5 \mu \mathrm{M}$
\end{tabular}

Positive control

\begin{tabular}{ccccc}
\hline \multicolumn{2}{c}{ Tail length $(\mu \mathrm{M})$} & \multicolumn{2}{c}{ Tail moment } \\
\cline { 1 - 2 } \cline { 5 - 5 } HeLa & MS751 & & HeLa & MS751 \\
\hline $8.15 \pm 2.58$ & $5.45 \pm 3.42$ & & $1.54 \pm 0.42$ & $5.12 \pm 1.71$ \\
$16.46 \pm 4.41$ & $21.07 \pm 3.51$ & & $8.31 \pm 1.34$ & $15.09 \pm 3.22$ \\
$30.01 \pm 5.21^{\mathrm{a}}$ & $48.42 \pm 9.52^{\mathrm{a}}$ & & $11.42 \pm 3.52^{\mathrm{a}}$ & $25.66 \pm 3.16^{\mathrm{a}}$ \\
$39.70 \pm 7.44^{\mathrm{a}}$ & $57.48 \pm 8.87^{\mathrm{a}}$ & & $19.33 \pm 1.72^{\mathrm{a}}$ & $33.76 \pm 4.21^{\mathrm{a}}$ \\
$56.24 \pm 10.47^{\mathrm{a}}$ & $72.06 \pm 4.70^{\mathrm{a}}$ & & $28.25 \pm 2.46^{\mathrm{a}}$ & $36.31 \pm 2.99^{\mathrm{a}}$ \\
$87.50 \pm 4.23^{\mathrm{a}}$ & $80.08 \pm 2.82^{\mathrm{a}}$ & & $35.27 \pm 3.34^{\mathrm{a}}$ & $43.08 \pm 6.36^{\mathrm{a}}$ \\
\end{tabular}

Data are expressed as the mean \pm standard error of the mean of tail length and tail moment of the HeLa and MS751 cells in the alkaline comet assay. ${ }^{a} \mathrm{P}<0.01$, vs. negative control $(0 \mu \mathrm{M}$ ginsenoside-Rg5). represent the significance of DNA damage. P-values refer to the comparison of baseline independent characteristics. Positive control, N-methyl-N-nitro-N-nitrosoguanidine; negative control, phosphate-buffered saline (0 $\mu \mathrm{M}$ ginsenoside- $\operatorname{Rg} 5)$.

A

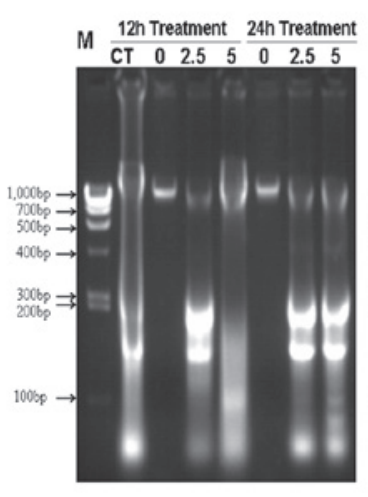

HeLa cells

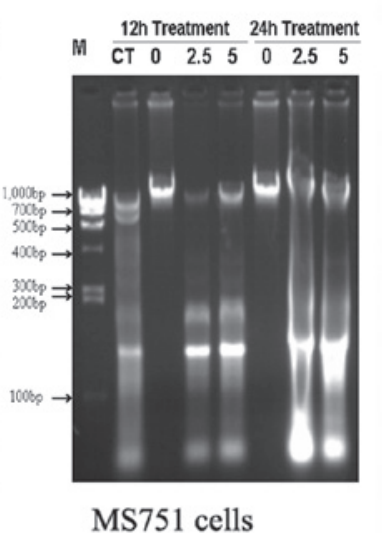

B

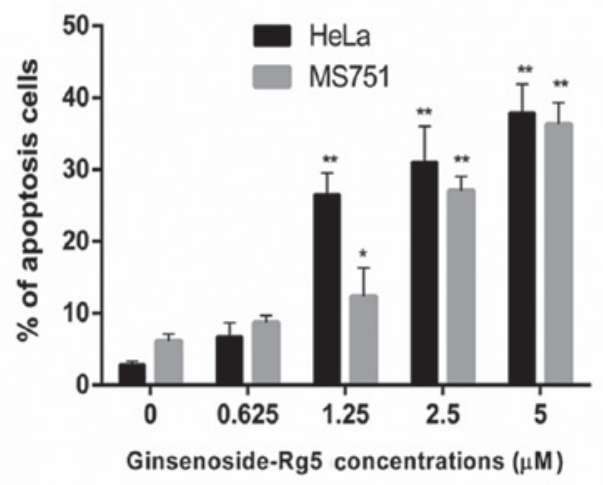

C
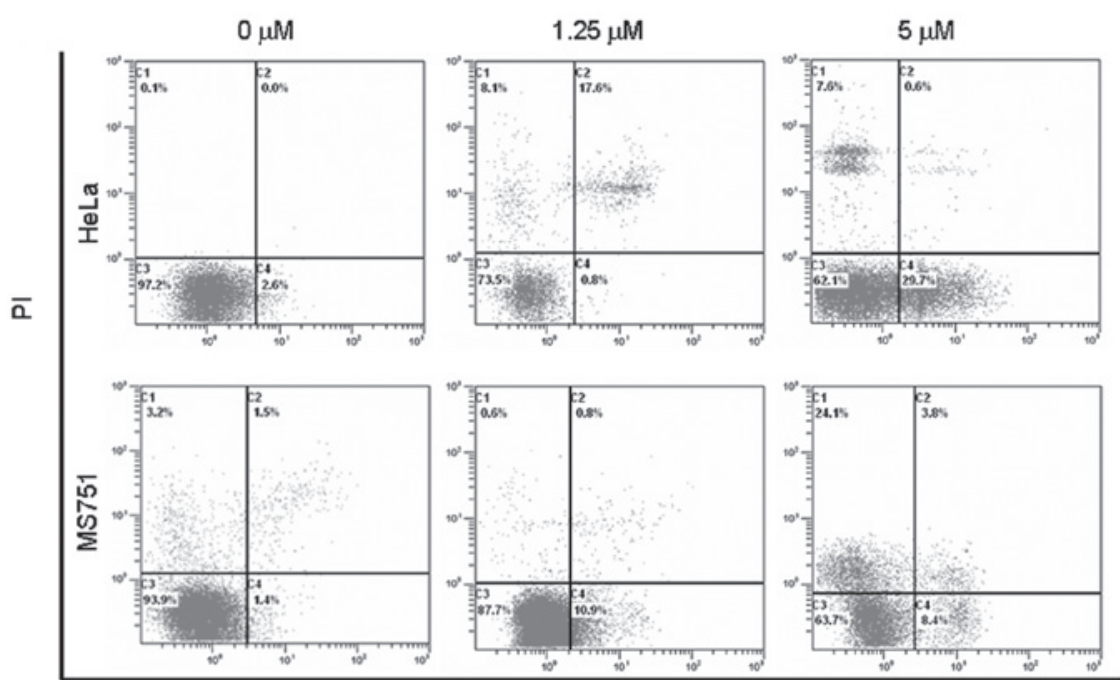

Annexin-V

Figure 3. Ginsenoside-Rg5 induces apoptosis in HeLa and MS751 cells. (A) Apoptosis-associated DNA fragmentation in HeLa and MS751 cells. (B) Apoptotic rates of HeLa and MS751 cells treated with ginsenoside-Rg5 (0-5 $\mu \mathrm{M})$ and MNNG $(10 \mu \mathrm{M})$ for $24 \mathrm{~h}$. Data are expressed as the mean \pm standard error of the mean of three independent experiments. " $\mathrm{P}<0.05$ and ${ }^{* *} \mathrm{P}<0.01$, vs. negative control $(0 \mu \mathrm{M}$ ginsenoside-Rg5). P-values refer to the comparison of baseline independent characteristics. (C) Flow cytometric analysis of apoptosis using Annexin-V and PI double-staining. MNNG, N-methyl-N-nitro-N-nitrosoguanidin; M, marker of DNA ladder; CT, positive control (10 $\mu \mathrm{M}$ MNNG); PI, propidium iodide. 

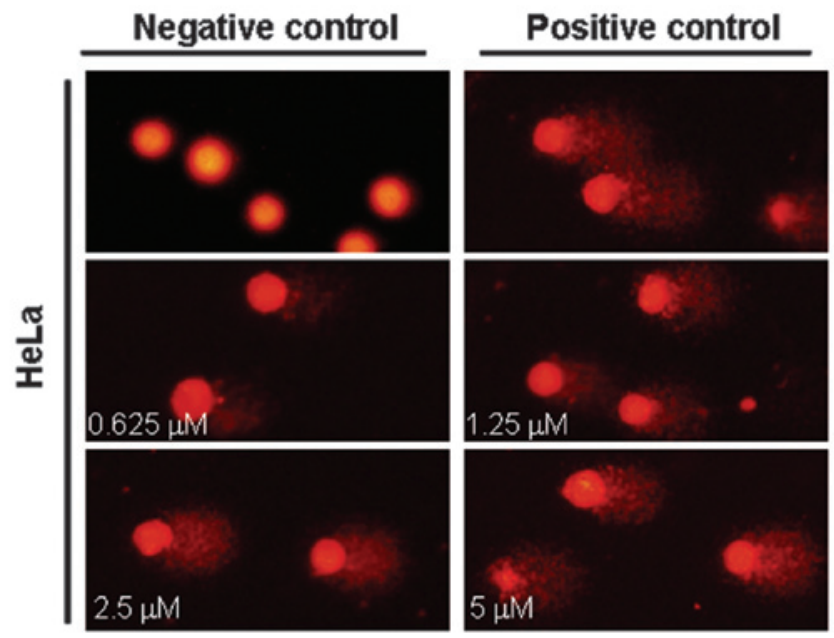

\begin{tabular}{|c|c|}
\hline $\begin{array}{c}\text { Negative } \\
\text { control }\end{array}$ & 6.1 \\
\hline $\begin{array}{c}\text { positive } \\
\text { control }\end{array}$ & 93.7 \\
\hline $\begin{array}{c}\text { Ginsenosi } \\
\text { des- } \\
\text { Rg5 }(\mu \mathrm{M})\end{array}$ & $\begin{array}{c}\% \text { comet } \\
\text { cells }^{+}\end{array}$ \\
\hline 0.625 & 35.9 \\
\hline 1.25 & 54.0 \\
\hline 2.5 & 62.7 \\
\hline 5 & 76.4 \\
\hline
\end{tabular}
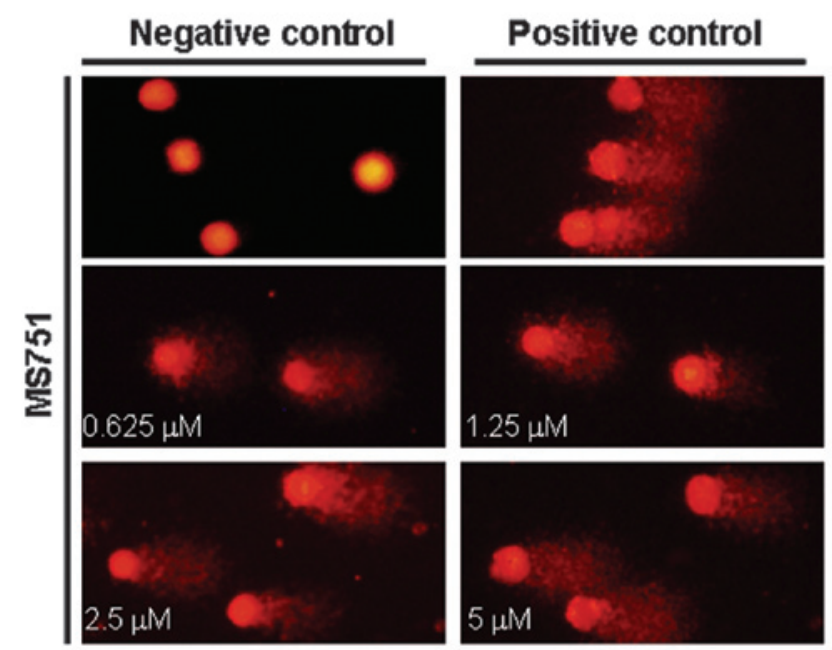

\begin{tabular}{|c|c|}
\hline $\begin{array}{c}\text { Negative } \\
\text { control }\end{array}$ & 4.5 \\
\hline $\begin{array}{c}\text { positive } \\
\text { control }\end{array}$ & 87.0 \\
\hline $\begin{array}{c}\text { Ginsenosi } \\
\text { des- } \\
\text { Rg5 }(\mu \mathrm{M})\end{array}$ & $\begin{array}{c}\% \text { comet } \\
\text { cells }\end{array}$ \\
\hline 0.625 & 20.1 \\
\hline 1.25 & 30.6 \\
\hline 2.5 & 46.0 \\
\hline 5 & 66.3 \\
\hline
\end{tabular}

Figure 4. Comet images (magnification, $\mathrm{x} 200$ ) of alkaline gel electrophoresis demonstrating DNA damage in the HeLa and MS751 cells. Treatment with $10 \mu \mathrm{M}$ $\mathrm{N}$-methyl-N-nitro-N-nitrosoguanidin was used as a positive control and 300 cells were counted at each concentration.

smooth margins and intact nuclei. The comet frequencies in the HeLa and MS751 cells were 6.1 and $4.5 \%$, respectively. In the cells treated with ginsenoside-Rg5, the DNA comets exhibited broom-shaped tails. The percentages of comet-positive HeLa and MS751 cells significantly increased at concentrations between 0 and $5 \mu \mathrm{M}$ compared with the negative control (Fig. 4).

The mean \pm SEM of the tail length and tail moment in the HeLa and MS751 cells are shown in Table I. These results indicated that the cells, which were exposed to different concentrations of ginsenoside-Rg5, exhibited significantly higher DNA damage $(\mathrm{P}<0.01)$ compared with the control samples. In these cell lines, ginsenoside- $\mathrm{Rg} 5$ significantly increased the tail length $(\mathrm{P}<0.01)$ and tail moment $(\mathrm{P}<0.01)$ when used at concentrations of 1.25 to $5 \mu \mathrm{M}$.

$\gamma H 2 A X$ foci reveal the induction of DNA DSBs by ginsenoside-Rg5. The phosphorylation of histone $\mathrm{H} 2 \mathrm{AX}$ foci formation has been suggested as a sensitive way to detect DNA DSBs (27). A threshold of four or more $\gamma \mathrm{H} 2 \mathrm{AX}$ foci/cell is optimal for determining the extent of DNA damage (28). Immunofluorescent images of histone $\mathrm{H} 2 \mathrm{AX}$ phosphorylation in the $\gamma \mathrm{H} 2 \mathrm{AX}$-stained HeLa and MS751 cells are shown in Fig. 5A. Ginsenoside-Rg5 caused a concentration-dependent induction of $\gamma \mathrm{H} 2 \mathrm{AX}$ foci. In the control, the HeLa and MS751 cells had few $\gamma \mathrm{H} 2 \mathrm{AX}$-positive foci in the nuclei and there were $\sim 5.5 \%$ cells containing over four foci (Fig. 5B). All treatments with ginsenoside-Rg5 and MNNG induced the formation of foci and increased the percentages of $\gamma \mathrm{H} 2 \mathrm{AX}$-positive cells. In addition, ginsenoside-Rg5 and $\mathrm{MNNG}$ exhibited distinct concentration-dependent effects $(\mathrm{P}<0.01)$ on the formation of $\gamma \mathrm{H} 2 \mathrm{AX}$ foci in the HeLa and MS751 cells (Fig. 5B).

\section{Discussion}

Conventional chemotherapeutic agents are often toxic to tumor cells and normal cells, which limits their therapeutic use. The identification of anticancer compounds from natural products offers a promising alternative to the use of synthetic compounds due to their favored safety and efficacy (29). Several preclinical and clinical studies have demonstrated the anticancer potential of Panax ginseng, which has been used clinically in China for thousands of years (19). In addition, ginseng is used to combat stress, fatigue, oxidizing agents, cancer and diabetes mellitus (30). The antitumor efficacy of ginseng is attributed mainly to the presence of saponins, also termed ginsenosides, which induce cell death and metastasis. Over 30 ginsenosides, which are triterpene derivatives, have been isolated from the ginseng saponin fraction and 
$\mathbf{A}$

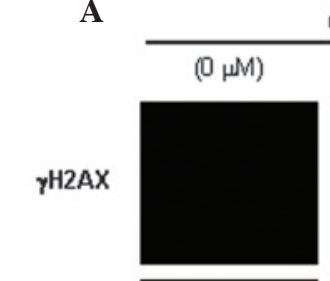

DAPI
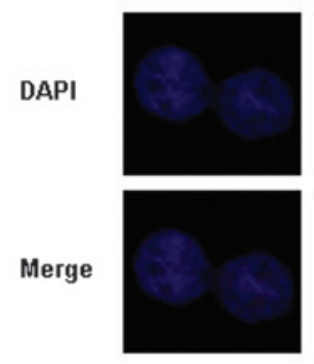

Ginsenosides-Rg5
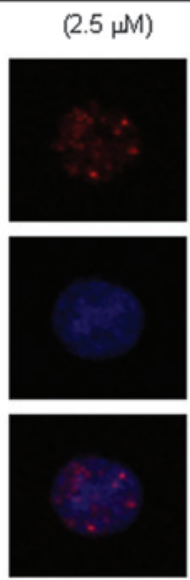

$(5 \mu \mathrm{M})$
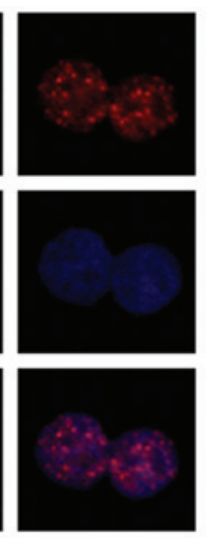
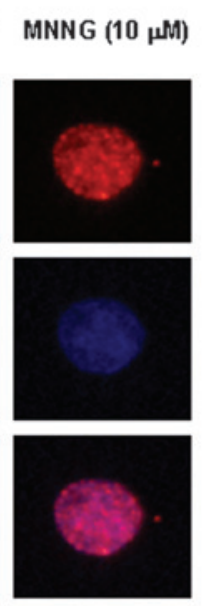

B
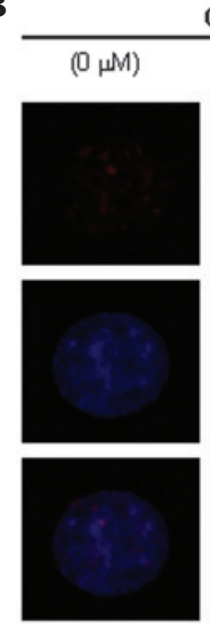

Ginsenosides-Rg5

$(2.5 \mu \mathrm{M})$
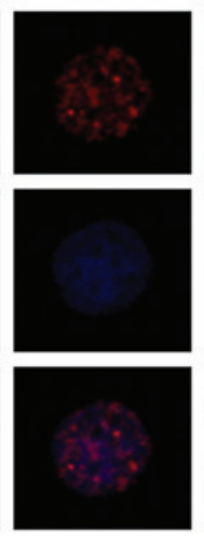

$(5 \mu \mathrm{M})$
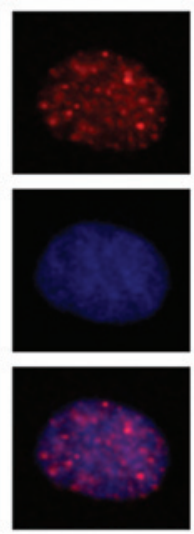

MNNG (10 $\mu \mathrm{M})$
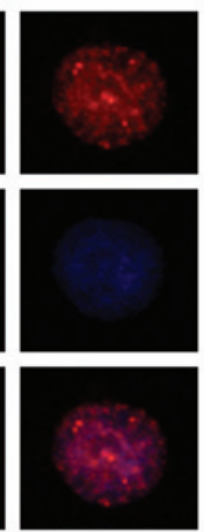

C

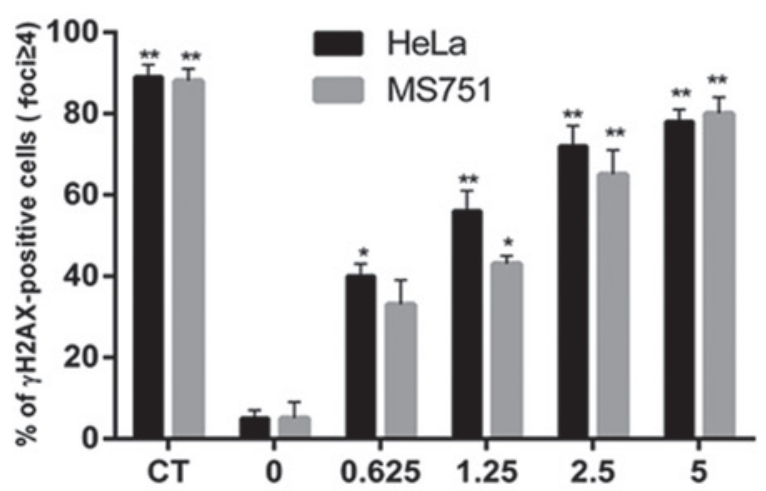

Ginsenoside-Rg5 concentrations $(\mu \mathrm{M})$

Figure 5. DNA double-strand breaks were visualized using $\gamma \mathrm{H} 2 \mathrm{AX}$ foci formation in the HeLa and MS751 cells. (A) Images of $\gamma \mathrm{H} 2 \mathrm{AX}$ foci formation in cells. Anti- $\gamma \mathrm{H} 2 \mathrm{AX}$ monoclonal antibodies were used to detect DNA damage foci immunofluorescence and DAPI was used for nuclei staining (magnification, $\mathrm{x} 400$ ). (B) Percentages of $\gamma \mathrm{H} 2 \mathrm{AX}$-positive cells were measured following treatment with $10 \mu \mathrm{M}$ MNNG (CT) and $0,0.625,1.25,2.5$ or $5 \mu \mathrm{M}$ ginsenoside-Rg5 for $24 \mathrm{~h}$. Data are expressed as the mean \pm standard error of the mean of three independent experiments. ${ }^{*} \mathrm{P}<0.05$ and ${ }^{* *} \mathrm{P}<0.01$, compared with the negative control. CT, positive control; MNNG, N-methyl-N-nitro-N-nitrosoguanidin; DAPI, 4',6-diamidino-2-phenylindole.

the chemical structures of the individual ginsenosides have been identified (15). Several types of eukaryotic cell death, including apoptosis, autophagy, paraptosis, mitotic catastrophe and necrosis have been recognized (31-33), of which apoptosis is the most common mechanism of cell death. Different types of ginsenoside induce apoptosis through a variety of signaling cascades. Ginsenoside-Rh2 and ginsenoside-Rg3 induce apoptosis in A549 lung adenocarcinoma cells, prostate cancer cells (34), hepatoma cells (35) and colorectal cancer cells (36). The induction of apoptosis by other ginsenosides, including $\mathrm{Rb} 2$, Rc and RS4, in different types of human tumor cell lines has also been observed $(37,38)$. These findings suggest that the induction of tumor cell apoptosis by ginsenosides may be one of the mechanisms through which these compounds exert their antitumor effects. However, only a few studies have investigated the effects of ginsenosides and, in particular, ginsenoside-Rg5 in human cervical cancer.

Apoptosis, or programmed cell death, is the result of a highly complex cascade of cellular events that result in chromatin condensation and DNA fragmentation (39). It is a fundamental cellular event during development and is essential for radiation or drug-induced cytotoxicity, which is characterized by the cleavage of chromatin DNA into internucleosomal fragments. In the present study, denaturing urea PAGE was used to detect DNA fragmentation and the rate of apoptosis was measured using flow cytometry by double-labeling with annexin V and PI. The data demonstrated that ginsenoside- Rg5 caused concentration- and time-dependent increases in DNA fragmentation.

In addition, the majority of evidence has indicated that ginsenosides induce cell cycle arrest and apoptosis in mammalian tumor cells $(35,40)$. However, few studies have described the genotoxicity of ginsenosides. Thus, the present study investigated the induction of DNA damage by ginsenoside-Rg5 in human cervical cancer cell lines in vitro by using alkaline comet assays and measuring $\gamma \mathrm{H} 2 \mathrm{AX}$ foci formation. The alkaline comet assay, a single-cell gel electrophoresis, is a method used to detect DNA strand breaks (41). Additionally, the formation of DNA DSBs induces $\gamma \mathrm{H} 2 \mathrm{AX}$ aggregation in the nucleus, thus, the measurement of $\gamma \mathrm{H} 2 \mathrm{AX}$ foci formation may be a sensitive method for the detection of DNA DSBs (42). In the present study, these assays revealed concentration-dependent increases in DNA damage, as evidenced by an increase in comet tail sizes with a concomitant reduction in head sizes in the comet assay, as well as an increased number of $\gamma \mathrm{H} 2 \mathrm{AX}$-positive cells 
in response to ginsenoside- $\mathrm{Rg} 5$ treatment. Thus, these results revealed that the presence of $\gamma \mathrm{H} 2 \mathrm{AX}$ foci may be indicative of DSBs, confirmed by the comet assay. These results were consistent with those observed in previous studies $(16,17)$, indicating that ginsenoside-Rg5 has antiproliferative and apoptotic activities in cancer cells.

In conclusion, the present study demonstrated that ginsenoside- $\operatorname{Rg} 5$ was anticarcinogenic, inducing cell DNA damage and apoptosis in vitro, and the DNA damage induced by ginsenoside-Rg5 may be associated with apoptosis. The results of the present study confirmed the antitumor effects of ginsenoside- $\operatorname{Rg} 5$ and the potential of ginsenoside- $\operatorname{Rg} 5$ as an agent of chemotherapeutic activity in human cervical cancer cells.

\section{References}

1. Saslow D, Castle PE, Cox JT, et al: American Cancer Society Guideline for human papillomavirus (HPV) vaccine use to prevent cervical cancer and its precursors. CA Cancer J Clin 57: 7-28, 2007.

2. Steben M and Duarte-Franco E: Human papillomavirus infection: epidemiology and pathophysiology. Gynecol Oncol 107: S2-S5, 2007.

3. Long HJ 3rd: Management of metastatic cervical cancer: review of the literature. J Clin Oncol 25: 2966-2974, 2007.

4. Brinkman JA, Caffrey AS, Muderspach LI, Roman LD and Kast WM: Inhibitory effect of ginsenoside Rg5 and its metabolite ginsenoside Rh3 in an oxazolone induced mouse chronic dermatitis model. Eur J Gynaecol Oncol 26: 129142 2005.

5. Leitao MM Jr and Chi DS: Recurrent cervical cancer. Curr Treat Options Oncol 3: 105-111, 2002.

6. Yang J, Li J, Sun M and Chen K: Studies of traditional Chinese medicine monomer on HeLa cell of cervical cancer. Pak J Pharm Sci 27 (4 Suppl): 1063-1068, 2014.

7. Cohen I, Tagliaferri M and Tripathy D: Traditional Chinese medicine in the treatment of breast cancer. Semin Oncol 29: 563-574, 2002

8. Li X, Yang G, Li X, et al: Traditional Chinese medicine in cancer care: a review of controlled clinical studies published in Chinese. PloS One 8: e60338, 2013

9. Yang G, Li X, Li X, et al: Traditional chinese medicine in cancer care: a review of case series published in the chinese literature. Evid Based Complement Alternat Med 2012: 7510-7546, 2012.

10. Liu J, Li X, Liu J, Ma L, Li X and Fønneb $\varnothing$ V: Traditional Chinese medicine in cancer care: a review of case reports published in Chinese literature. Forsch Komplementarmed 18: 257-263, 2011

11. Kwon SW, Han SB, Park IH, Kim JM, Park MK and Park JH: Liquid chromatographic determination of less polar ginsenosides in processed ginseng. J Chromatogr A 921: 335-339, 2001.

12. Kim SN, Ha YW, Shin H, Son SH, Wu SJ and Kim YS: Simultaneous quantification of 14 ginsenosides in Panax ginseng C.A. Meyer (Korean red ginseng) by HPLC-ELSD and its application to quality control. J Pharm Biomed Anal 45: 164-170, 2007.

13. Yun TK, Lee YS, Lee YH, Kim SI and Yun HY: Anticarcino genic effect of Panax ginseng C.A. Meyer and identification of active compounds. J Korean Med Sci 16: S6-S18, 2001.

14. Kang KS, Kim HY, Baek SH, et al: Study on the hydroxyl radical scavenging activity changes of ginseng and ginsenoside-Rb2 by heat processing. Biol Pharm Bull 30: 724-728, 2007.

15. Nag SA, Qin JJ, Wang W, et al: Ginsenosides as anticancer agents: In vitro and in vivo activities, structure-activity relationships, and molecular mechanisms of action. Front Pharmacol 3: 25, 2012.

16. Lee KY,Lee YH, Kim SI, Park JH and Lee SK: Ginsenoside-Rg5 suppresses cyclin E-dependent protein kinase activity via up-regulating p21Cip/WAF1 and down-regulating cyclin E in SK-HEP-1 cells. Anticancer Res 17: 1067-1072, 1997.

17. Shin YW, Bae EA and Kim DH: Inhibitory effect of ginsenoside $\mathrm{Rg} 5$ and its metabolite ginsenoside $\mathrm{Rh} 3$ in an oxazolone-induced mouse chronic dermatitis model. Arch Pharm Res 29: 685-690, 2006.
18. Kim TW,JohEH,KimB and Kim DH: Ginsenoside Rg5 ameliorates lung inflammation in mice by inhibiting the binding of LPS to toll-like receptor-4 on macrophages. Int Immunopharmacol 12: 110-116, 2012.

19. Kim EJ, Jung IH, Van Le TK, Jeong JJ, Kim NJ and Kim DH: Ginsenosides $\operatorname{Rg} 5$ and $\mathrm{Rh} 3$ protect scopolamine-induced memory deficits in mice. J Ethnopharmacol 146: 294-299, 2013.

20. Lee YY, Park JS, Jung JS, Kim DH and Kim HS: Antiinflammatory effect of ginsenoside Rg5 inlipopolysaccharide-stimulated BV2 microglial cells. Int J Mol Sci 14: 9820-9833, 2013.

21. Kawai K, Liu SX, Tyurin VA, et al: Antioxidant and antiapoptotic function of metallothioneins in HL-60 cells challenged with copper nitrilotriacetate. Chem Res Toxicol 13: 1275-1286, 2000.

22. Wu SB, Su JJ, Sun LH, et al: Triterpenoids and steroids from the fruits of Melia toosendan and their cytotoxic effects on two human cancer cell lines. J Natl Prod 73: 1898-1906, 2010.

23. Nakadai A, Li Q and Kawada T: Chlorpyrifos induces apoptosis in human monocyte cell line U937. Toxicology 224: 202-209, 2006.

24. Guanggang X, Diqiu L, Jianzhong Y, et al: Carbamate insecticide methomyl confers cytotoxicity through DNA damage induction. Food Chem Toxicol 53: 352-358, 2013.

25. Zhang YH, Li HD, Li B, Jiang SD and Jiang LS: Ginsenoside Rg3 induces DNA damage in human osteosarcoma cells and reduces MNNG-induced DNA damage and apoptosis in normal human cells. Oncol Rep 31: 919-925, 2014.

26. Wu GS, Lu JJ, Guo JJ, et al: Ganoderic acid DM, a natural triterpenoid, induces DNA damage, G1 cell cycle arrest and apoptosis in human breast cancer cells. Fitoterapia 83: 408-414, 2012.

27. Sokolov MV, Smilenov LB, Hall EJ, Panyutin IG, Bonner WM and Sedelnikova OA: Ionizing radiation induces DNA double-strand breaks in bystander primary human fibroblasts. Oncogene 24: 7257-7265, 2005 .

28. Parry MC, Bhabra G, Sood A, et al: Thresholds for indirect DNA damage across cellular barriers for orthopaedic biomaterials. Biomaterials 31: 4477-4483, 2010.

29. Toh DF, Patel DN, Chan EC, Teo A, Neo SY and Koh HL: Anti-proliferative effects of raw and steamed extracts of Panax notoginseng and its ginsenoside constituents on human liver cancer cells. Chin Med 6: 4, 2011.

30. Yue PY, Mak NK, Cheng YK, et al: Pharmacogenomics and the Yin/Yang actions of ginseng: anti-tumor, angiomodulating and steroid-like activities of ginsenosides. Chin Med 2: 6, 2007.

31. Bras M, Queenan B and Susin SA: Programmed cell death via mitochondria: different modes of dying. Biochemistry (Mosc) 70: 231-239, 2005.

32. Broker LE, Kruyt FA and Giaccone G: Cell death independent of caspases: a review. Clin Cancer Res 11: 3155-3162, 2005.

33. Edinger AL and Thompson CB: Death by design: apoptosis, necrosis and autophagy. Curr Opin Cell Biol 16: 663-669, 2004.

34. Kim HS, Lee EH, Ko SR, Choi KJ, Park JH and Im DS: Effects of ginsenosides $\mathrm{Rg} 3$ and $\mathrm{Rh} 2$ on the proliferation of prostate cancer cells. Arch Pharm Res 27: 429-435, 2004.

35. Park HM, Kim SJ, Kim JS and Kang HS: Reactive oxygen species mediated ginsenoside Rg3- and Rh2-induced apoptosis in hepatoma cells through mitochondrial signaling pathways. Food Chem Toxicol 50: 2736-2741, 2012.

36. Li B, Zhao J, Wang CZ, et al: Ginsenoside Rh2 induces apoptosis and paraptosis-like cell death in colorectal cancer cells through activation of p53. Cancer Lett 301: 185-192, 2011.

37. Kim SE, Lee YH, Park JH and Lee SK: Ginsenoside-Rs4, a new type of ginseng saponin concurrently induces apoptosis and selectively elevates protein levels of p53 and p21WAF1 in human hepatoma SK-HEP-1 cells. Eur J Cancer 35: 507-511, 1999.

38. Oh SH and Lee BH: A ginseng saponin metabolite-induced apoptosis in HepG2 cells involves a mitochondria-mediated pathway and its downstream caspase- 8 activation and Bid cleavage. Toxicol Appl Pharmacol 194: 221-229, 2004.

39. Robertson JD and Orrenius S: Role of mitochondria in toxic cell death. Toxicology 181-182: 491-496, 2002.

40. Poon PY, Kwok HH, Yue PY, et al: Cytoprotective effect of 20S-Rg3 on benzo[a]pyrene-induced DNA damage. Drug Metab Dispos 40: 120-129, 2012.

41. Cotelle S and Férard JF: Comet assay in genetic ecotoxicology: a review. Environ Mol Mutagen 34: 246-255, 1999.

42. Yu Y, Zhu W, Diao H, Zhou C, Chen FF and Yang J: A comparat ive study of using comet assay and gammaH2AX foci formation in the detection of N-methyl-N'-nitro-N-nitrosoguanidine-induced DNA damage. Toxicology In Vitro 20: 959-965, 2006. 